Published in final edited form as:

ACS Infect Dis. 2019 November 08; 5(11): 1896-1906. doi:10.1021/acsinfecdis.9b00222.

\title{
Toward Broad Spectrum DHFR inhibitors Targeting Trimethoprim Resistant Enzymes Identified in Clinical Isolates of Methicillin- Resistant Staphylococcus aureus
}

\author{
Stephanie M. Reeve ${ }^{1}$, Debjani $\mathbf{S i}^{1}$, Jolanta Krucinska ${ }^{1}$, Yongzhao Yan ${ }^{1}$, Kishore \\ Viswanathan $^{1}$, Siyu Wang ${ }^{2,3}$, Graham T. Holt ${ }^{2,3}$, Marcel S. Frenkel ${ }^{4}$, Adegoke A. Ojewole ${ }^{2,3}$, \\ Alexavier Estrada ${ }^{1}$, Sherry S. Agabiti ${ }^{1}$, Jeremy B. Alverson ${ }^{5}$, Nathan D. Gibson ${ }^{5}$, Nigel D. \\ Priestly $^{5}$, Andrew J. Wiemer ${ }^{1}$, Bruce R. Donald ${ }^{2,4,6}$, Dennis L. Wright ${ }^{1,7,{ }^{*}}$ \\ ${ }^{1}$ Department of Pharmaceutical Sciences, University of Connecticut, 69 N. Eagleville Road, \\ Storrs, CT 06269 USA \\ ${ }^{2}$ Department of Computer Science, Duke University, 308 Research Drive, Durham, NC 27708 \\ USA \\ ${ }^{3}$ Program in Computational Biology and Bioinformatics, Duke University, 101 Science Drive, \\ Durham, NC 27708 USA \\ ${ }^{4}$ Department of Biochemistry, Duke University Medical Center, 255 Nanaline H. Duke, Durham, \\ NC 27710 USA \\ ${ }^{5}$ Department of Chemistry, University of Montana, 32 Campus Drive, Missoula, MT 59812, USA \\ ${ }^{6}$ Department of Chemistry, Duke University, 124 Science Drive, Durham, NC 27708 USA \\ ${ }^{7}$ Department of Chemistry, University of Connecticut, 55 N. Eagleville Road, Storrs, CT 06269 \\ USA
}

\begin{abstract}
The spread of plasmid borne resistance enzymes in clinical Staphylococcus aureus isolates is rendering trimethoprim and iclaprim, both inhibitors of dihydrofolate reductase (DHFR), ineffective. Continued exploitation of these targets will require compounds that can broadly inhibit
\end{abstract}

\footnotetext{
*Corresponding Author contact: dennis.wright@uconn.edu.

Present/Current author addresses

SMR: Department of Chemical Biology and Therapeutics, St. Jude Children's Research Hospital, Memphis, Tennessee, USA

YY: Microbiotix, Inc. Worchester, Massachusetts, USA

KV: MacDermid Ethone, Waterbury, Connecticut, USA

SS: Department of Genetics, Yale University, New Haven, Connecticut, USA

Author contributions

SMR: Strain characterization and susceptibilities, enzyme inhibition, protein purification and protein crystallography. DS, YY and

$\mathrm{KV}$ : synthesis and characterization of novel chemical matter. JK: protein purification and enzyme kinetic experiments. SW, GTH and MSF: DfrG homology models. SS: DHFR expression profiling. NDG and JBA: preformed cytotoxicity assays. NDP: oversaw cytotoxicity experiments. AW: oversaw DHFR expression and western blotting experiments. BRD: oversaw computational experiments and DLW directed biology and synthetic chemistry. SMR, DJ, and DLW wrote and SMR, DJ, JK, DLW edited the manuscript.

Ancillary Information

PDB Codes

DfrB:NADPH:14|PDB ID: 6PBO

DfrB:NADPH:Methotrexate | PDB ID: 6P9Z
} 
these resistance-conferring isoforms. Using a structure-based approach, we have developed a novel class of ionized non-classical antifolates (INCAs) that capture the molecular interactions that have been exclusive to classical antifolates. These modifications allow for a greatly expanded spectrum of activity across these pathogenic DHFR isoforms, while maintaining the ability to penetrate the bacterial cell wall. Using biochemical, structural and computational methods, we are able to optimize these inhibitors to the conserved active sites of the endogenous and trimethoprim resistant DHFR enzymes. Here, we report a series of INCA compounds that exhibit low nanomolar enzymatic activity and potent cellular activity with human selectivity against a panel of clinically relevant TMPR ${ }^{\mathrm{R}} \mathrm{MRSA}$ isolates.

\section{Graphical Abstract}

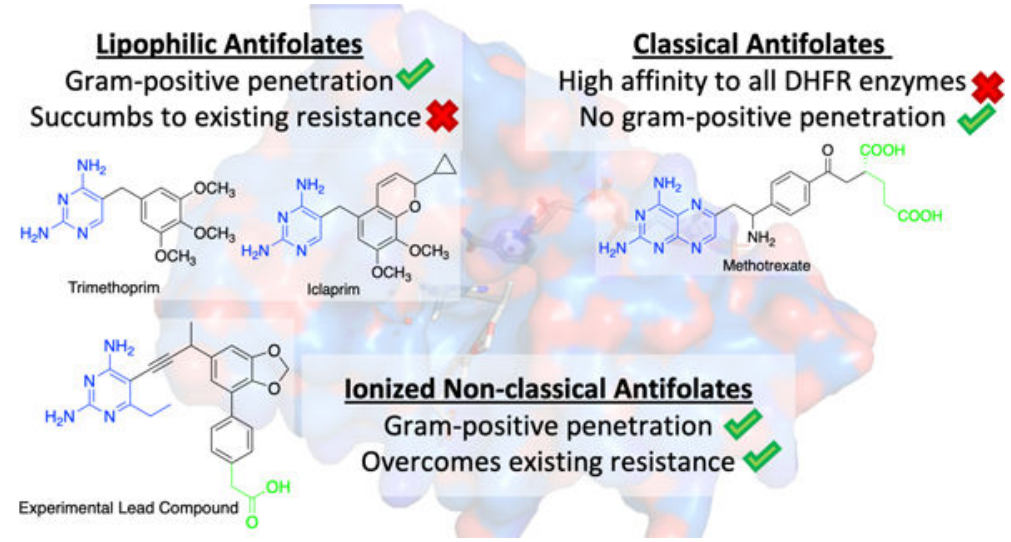

\section{Keywords}

Antifolate Resistance; Antibiotic Discovery; Iclaprim; Drug Discovery; Antibiotics; Ionized nonclassical antifolates

Antibacterial resistance is a growing healthcare and public health crisis worldwide. The rapid dissemination of antibiotic resistance has diminished the efficacy of many once reliable therapeutics. In fact, resistance to every class of antibiotics has been observed clinically. Recently, The Review on Antimicrobial Resistance projected that drug resistant infections will be responsible for more than 10 million deaths a year by 2050 and cost the global economy over 100 trillion USD. Among the most prevalent pathogens that have been identified as particular concern are methicillin and vancomycin-resistant strains of Staphylococcus aureus ${ }^{1}$.

Methicillin resistant Staphylococcus aureus (MRSA), an opportunistic gram-positive bacterium, is the leading cause of healthcare associated infections as well as invasive systemic infections, pneumonia and skin and soft tissue infections (SSTIs) worldwide. The CDC reports over 80,000 invasive MRSA infections annually in the United States, more than 11,000 of which are fatal, which has prompted the CDC to classify drug resistant MRSA as a 'Serious Threat'2. 
The antifolate combination of trimethoprim (TMP) and sulfamethoxazole (SMX) (cotrimethoxazole), marketed as Bactrim or Septra, is a first line treatment for community acquired skin and soft tissue MRSA infections. Trimethoprim targets dihydrofolate reductase (DHFR) which is responsible for the NADPH-dependent reduction of dihydrofolate (DHF) to tetrahydrofolate (THF). DHFR is the only source for the recycling of THF in the cell. When employed in conjunction with sulfamethoxazole, which targets dihydropteroate synthase, this powerful synergistic antibacterial combination results in potent coverage against both Gram-negative and Gram-positive pathogens. Due to its broad spectrum of activity, oral bioavailability and general tolerability, prescriptions of TMP-SMX numbered more than 21 million in 2013, putting it in the group of top ten oral antibiotics prescribed $^{3}$.

Currently, trimethoprim is the sole FDA-approved antibiotic targeting DHFR. A second compound, iclaprim, a structurally similar DHFR inhibitor with anti-staphylococcal activity, has recently completed a Phase III clinical trial for acute bacterial skin and skin structure (ABSSI) infections ${ }^{4}$. DHFR inhibitors are historically grouped into two classes: lipophilic and classical. Trimethoprim and iclaprim are lipophilic antifolates as they contain a 2,4diaminopyrimidine pharmacophore and passively diffuse into the cytosolic space. Methotrexate (MTX) and pemetrexed, both chemotherapeutics, are known as classical antifolates as they possess a glutamate moiety in their structure, Figure 1. As mimics of the natural substrate DHF, classical antifolates show high affinity to all DHFR enzymes, however due to the negatively charged glutamate tail (net charge $=-2$ ), these compounds must be actively transported into the cell via specific folate carriers. Since bacteria do not have these transport mechanisms, classical antifolates do not show significant antibacterial efficacy despite powerful inhibition of bacterial DHFR.

Trimethoprim resistance in $S$. aureus was first recognized in the 1980s following its clinical introduction in 1968. In the 1990s, two primary resistance mechanisms were identified as conferring clinical TMP resistance (TMPR): point mutations in the endogenous TMP sensitive (TMP ${ }^{\mathrm{S}}$ ) chromosomal DHFR gene $\mathrm{dfr} B$ and the acquisition of an innately resistant DHFR gene, $d f_{r} A^{5,6}$. Recently two additional plasmid-encoded DHFR resistance genes, $d f r G$ and $d f r K$, began appearing in MRSA infections both abroad and domestically. The $d f r G$, gene, encoding the TMP ${ }^{\mathrm{R}}$ DHFR enzyme DfrG, was first isolated in Thailand and later isolated in South Africa where its import to Europe was tracked via epidemiological studies $^{7,8}$. The TMPR enzyme DfrK, coded by $d f r K$, was predominately associated with agricultural infections and began appearing in farmers and children in farm villages in Ireland ${ }^{9}$. We recently identified $d f r G$ and $d f r K$ in clinical strains of MRSA from Connecticut hospitals, with $d f r G$ being the predominant resistance determinant ${ }^{10}$. Our observations were mimicked in other studies identifying DfrG in as many as $78 \%$ of $\mathrm{TMP}^{\mathrm{R}}$ isolates followed by DfrA and DfrA variants. Strains with mutant DfrB were seldom isolated ${ }^{11,12}$.

We have been developing next generation DHFR inhibitors against TMP-resistant Grampositive ${ }^{13,14}$, Gram-negative ${ }^{15,16}$ and mycobacterial ${ }^{17}$ pathogens. These compounds feature a 6-ethyl-2,4-diaminopyrimidine moiety linked to a meta-biaryl system through an acetylenic linker (Figure 1). Recently, we disclosed a distinct class of antifolates designated as ionized non-classical antifolates (INCA), that are characterized by acidic functionality on 
the distal phenyl ring able to capture the powerful interaction between the glutamate tail of classical antifolates and DHFR ${ }^{14}$. Importantly, this modification alters the charge distribution of INCAs to anionic/zwitterionic relative to earlier generations that are cationic/ neutral. This mono-carboxylate design allows us to partially exploit the key interactions used in substrate/classical antifolate binding while still maintaining the ability to passively penetrate the bacterial membrane. INCA leads exhibit strong potency against the wild-type and $\mathrm{TMP}^{\mathrm{R}}$ mutant enzymes as well as clinically isolated strains containing the newly discovered $d f r G$ and $d f r K$ genes ${ }^{10}$.

With the exception of iclaprim, there has been a notable lack of development of therapeutics targeting dihydrofolate reductase in the antibacterial space. Herein, we have report a series of INCA antifolates that directly target the endogenous and acquired DHFR isoforms that confer trimethoprim and iclaprim resistant phenotypes. Using biochemical, microbiological, structural and computational techniques we are able to assess these compounds as potential antibacterial therapeutics.

\section{Results and Discussion}

A panel of clinically isolated TMPR MRSA and their corresponding DHFR enzymes, representative of the resistance landscape reported in recent literature, was assembled for this study. This panel is comprised of isolates containing both a wild-type endogenous $d f r B$ gene as well as either $d f r A, d f r G$ or $d f r K \mathrm{TMP}^{\mathrm{R}}$ genes, Table 1 . The clinical isolates, which have been previously characterized, were collected during the course of routine clinical care from Connecticut hospitals, show unique clonality and exhibit diverse antibiotic phenotypes $^{10}$.

Of the enzymes discussed in this study, the origins, biochemical and structural features of DfrA have been best characterized ${ }^{6,19}$. DfrA has accumulated three important mutations compared to its TMPS S. epidermidis progenitor (F98Y, G43A and V31L) that are responsible for high-level TMP resistance. While the origins of DfrG and DfrK are still unknown, it is believed that these enzymes are related to Bacillus spp. DfrK and DfrG share a $90 \%$ sequence identity to each other, but only share around $40 \%$ sequence identity to DfrB and DfrA, Supplemental Figure S1. Despite low sequence identity, these enzymes show high homology within the folate binding site. With the exception of a Leu5 to Ile substitution in DfrA, DfrG, and DfrK, the residues that participate in hydrogen bonds with the substrate remain conserved throughout the acquired enzymes. A sequence alignment is reported in Supplemental Figure S2.

All clinical isolates used in this study exhibit high levels of antifolate resistance, Table 1. The $d f r G$ and $d f r K$ containing isolates, UCH121 and HH1184, confer the highest levels of resistance with MIC values of $>1000 \mu \mathrm{g} / \mathrm{mL}$ against trimethoprim and $>250 \mu \mathrm{g} / \mathrm{mL}$ against iclaprim. The $d f r A$ containing strain, $\mathrm{UCH} 115$, also succumbs to high level antifolate resistance with MIC values of $250 \mu \mathrm{g} / \mathrm{mL}$ for trimethoprim and $64 \mu \mathrm{g} / \mathrm{mL}$ for iclaprim. Minimally, the presence of these resistant enzymes in the clinical isolates results in an 800fold loss in cellular efficacy for these agents when compared to the TMPS comparator, 
ATCC43300. Importantly, iclaprim is unable to evade any of these prevalent TMP resistant elements, rendering the compound largely ineffective against existing $\mathrm{TMP}^{\mathrm{R}}$ isolates.

In addition to cellular evaluations of $d f r G, d f r K$ and $d f r A$ containing strains, their corresponding recombinant enzymes DfrG, DfrK and DfrA, were generated for kinetic and inhibitory enzymatic evaluations. Both the wild type DHFR and the TMPR enzymes display the typical hyperbolic progression of Michaelis-Menten kinetics. The initial rates for DHF were applied for determination of $K_{M}, k_{c a t}$ and $k_{c a l} / K_{M}$ as summarized in Table 2. Substrate binding affinities, $K_{M}(D H F)$ of DfrK and DfrG are very similar to that found in DfrB with $K_{M}$ values of $11.01,8.87$ and $13.35 \mu \mathrm{M}$, respectively. DfrA displays tighter interaction with DHF with approximately a two-fold decrease in $K_{M}$ with a value of $5.76 \mu \mathrm{M}$. The specificity constants $\left(k_{c a t} / K_{M}\right)$ of the TMP ${ }^{\mathrm{R}}$ enzymes are also highly comparable to those of the wild type. A two-fold higher efficiency of DfrA enzyme, with a $K_{c a t} / K_{M}$ of $0.72 \mu \mathrm{M}^{-1} / \mathrm{s}^{-1}$, is due to the increased binding affinity to DHF while the turnover rates for the other two TMPresistant enzymes are very similar relative to the wild type DHFR, Table 2.

The resistance phenotypes observed for trimethoprim and iclaprim in the clinical isolates were recapitulated in their enzyme inhibitory activities, Table 2 . DfrG conferred the highest level of resistance to both trimethoprim and iclaprim with $K_{i}$ values of 31,000 and 1,350 $\mathrm{nM}, \mathrm{a}>11,400$ and 774-fold loss when compared to DfrB. Likewise, DfrA and DfrK both exhibit steep losses in affinity toward trimethoprim with $K_{i}$ values of $820 \mathrm{nM}$ and $4,260 \mathrm{nM}$. Iclaprim maintains higher potency against DfrK and DfrA than with DfrG with $K_{i}$ values of 221 and $90 \mathrm{nM}$, respectively. Unlike the poor inhibitory activity of the lipophilic antifolates in these enzymes, methotrexate maintains potent activity regardless of DHFR identity with $K_{i}$ values of $0.71 \mathrm{nM}$ for DfrB and 1.8, 2.47 and $0.38 \mathrm{nM}$ for DfrG, DfrK and DfrA, respectively.

\section{Design and Evaluation of lonized Non-Classical Antifolates (INCAs).}

During the last decade, we have developed and evolved the propargyl-extended antifolates from TMP like derivatives ${ }^{20}$ to highly functionalized inhibitors tailored to the DfrB active site. Most recently, we have developed a new class of ionized non-classical antifolates (INCAs) featuring a distal benzoic acid that adds MTX-like character to the inhibitors, Figure $2^{10,14}$. These compounds are able to engage the Arg57 side chain through one direct and a water mediated hydrogen bonding interaction. Through structure-based drug design, we have been able to expand the structural diversity of experimental INCAs and establish a structure activity relationship between these benzoic acid inhibitors, interactions with Arg57 and potency. While these inhibitors have shown greatly improved potency over trimethoprim, the MIC discrepancy between the TMP ${ }^{\mathrm{R}}$ strains remain up to 64 -fold ${ }^{10}$. When designing across resistant targets, it is important that the MICs across target isoforms have only small deviation to ensure the widest possible coverage. Given the broad potency of MTX against the DfrA, DfrG and DfrK enzymes, it was hypothesized that fine tuning the interaction between the INCA carboxylate moiety and the conserved arginine sidechain would be a powerful strategy for achieving broad-based activity against these redundant DHFR containing isolates. 
In order to facilitate the refinement of our INCA leads, we first obtained a co-crystal structure of the DfrB in complex with NADPH and MTX to better understand the binding mode of MTX to the bacterial reductase. In this structure, MTX makes extensive hydrogen bonding interactions with the protein's active site including the Asp27 side chain, an active site water and the backbone carbonyls of Leu5 and Phe92. These contacts are supplemented with dual hydrogen bonds formed between the guanidinium side chain of Arg57 and the glutamate tail. The major structural difference between the human (PDB ID: 1DLS) ${ }^{21}$ and $S$. aureus structures is a loss of a hydrogen bond between the amide carbonyl of MTX and Asn64 side chain; this residue is replaced by a glycine in DfrB as well as the DfrA, DfrG and DfrK isoforms. Lipophilic antifolates, trimethoprim and iclaprim, rely heavily on the hydrogen bond interactions within the diaminopyrimidine binding pocket, as contacts with the distal Arg57 have always been an exclusive feature of classical antifolates. The potential value of adding this functionality to antifolates has been recognized as a tool to overcome resistance to point mutations, as this residue is unlikely to mutate without encountering a major fitness $\operatorname{cost}^{22}$.

We hypothesized that the placement of an additional carbon between the distal aryl ring and carboxylate would allow for a more productive MTX-like interaction. Therefore, a matched series of five benzoic acid and phenyl acetic acid inhibitors were synthesized for structural, biochemical and microbiological evaluations, Table 3. 10,13,14,16

The INCA series of compounds demonstrate excellent inhibitory activity against the wildtype and resistant enzymes, Table 4 . The phenyl acetic acid INCAs either retained or increased their potency for DfrB relative to their benzoic acid counterpart. Compound $6\left(\mathrm{R}_{1^{-}}\right.$ Cl) exhibited the most potent enzyme inhibition against DfrB with a $K_{i}$ of $1.2 \mathrm{nM}$, an 8-fold increase relative to its benzoic acid analog. When evaluated against TMPR enzymes, the INCAs were $>1000$-fold more potent than TMP and showed over 100-fold more inhibitory activity than iclaprim. Changing the substitution from $\mathrm{R}_{1}$-OMe $(\mathbf{3}, \mathbf{4})$ to $\mathrm{R}_{1}, \mathrm{R}_{2}$-dioxolane ( $\mathbf{1}$, 2) or $\mathrm{R}_{1}-\mathrm{Cl}(\mathbf{5}, \mathbf{6})$ had a positive effect across all three enzymes. Furthermore, all phenyl acetic acid INCAs showed enhanced inhibition against DfrA and DfrG when compared to their benzoic acid counterparts, with the most potent compound, $\mathbf{1 0}$ having a $K_{i}$ value of 2.2 nM for DfrA. For DfrK, all extended acid INCAs exhibited comparable activity to their benzoic acid partners. This observation supported our hypothesis that increases in proximity and flexibility creates better interactions between the ionized extended-carboxylates and the conserved arginine.

Ideally, new generation DHFR inhibitors would have sufficient selectivity over the human enzyme to avoid concomitant inhibition. Therefore, all INCAs were tested against human DHFR isoform (HuDHFR). From this data, it was apparent that the nature of substituents on the biphenyl ring system of INCAs have an immense effect on their inhibitory activities against human DHFR. For benzoic acids, moving the substitutions from $\mathrm{R}_{1}$-OMe (3) to any other position demonstrated increased selectivity, or decreased affinity towards HuDHFR. Extension of one carbon to the phenyl acetic acid improves the selectivity for $\mathrm{R}_{1}$-substituted ring systems but has a detrimental effect on other scaffolds. Notably, compound $\mathbf{6}$ has a 33fold increase in selectivity for the pathogenic enzymes compared to its benzoic acid analog, 5. 
All compounds were also evaluated for antibacterial inhibition against the panel of TMP and $\mathrm{TMP}^{\mathrm{R}}$ isolates. These compounds maintained potent activity against wild-type ATCC43300 quality control strains with MIC values ranging from 0.4 to $<0.001 \mu \mathrm{g} / \mathrm{mL}$, with the R1-Cl inhibitors ( 5 and $\mathbf{6}$ ) being most potent. In general, the extension from benzoic acid to phenyl acetic acid has only a minor effect (1-2 fold increase) on potencies against the wild-type strain. For UCH121 and HH1184, which contain the $d f r G$ and $d f r K$ resistance genes, MIC values range from $0.625-10$ and $0.3125-2.5 \mu \mathrm{g} / \mathrm{mL}$, respectively. Many of these compounds have MIC values less than $1 \mu \mathrm{g} / \mathrm{mL}$ against these strains, a $>400$ and $>1,600$ fold increase in potency compared to iclaprim and trimethoprim, respectively. For these strains, the majority of the phenyl acetic acid series were comparable to their benzoic acid partner.

The benefits of the phenyl acetic acid series are most pronounced in UCH115, the $d f r A$ containing strain. MICs in this strain range from $1.25-20 \mu \mathrm{g} / \mathrm{mL}$, with the extended acids exhibiting improved potency over the benzoic acid analogs. For example, compound 14, the extended acid $\mathrm{R}_{2}, \mathrm{R}_{3}$-dioxolane, has an MIC of $2.5 \mu \mathrm{g} / \mathrm{mL}$ corresponding to an 8 - fold increase in potency when compared to its benzoic acid partner, 13. Similarly the 1,2dioxolane extended acid, compound $\mathbf{2}$, improves potency against the $d f f A$ containing strain compared to $\mathbf{1}$, matching the activity trends observed with the purified enzymes. Importantly, the increased potency of these extended acid inhibitors puts all TMP ${ }^{\mathrm{R}}$ strains within 2 and 4-fold of each other, effectively bridging the large activity gap seen with the benzoic acid compounds.

An area of major importance in developing antibacterial DHFR inhibitors is achieving adequate selectivity over the human isoform. While the compounds tested here have less than 100-fold selectivity for the human isoform over the pathogenic enzyme, Table 4, these compounds exhibit very little mammalian toxicity when tested against both MCF-10 and HepG2 cell lines, Table 5. Most of the INCA compounds have $\mathrm{IC}_{50}$ values $>200 \mu \mathrm{g} / \mathrm{mL}$ in both cell lines. Compound 5 is the most cytotoxic compound tested with $\mathrm{IC}_{50}$ values of 49 and $99 \mu \mathrm{g} / \mathrm{mL}$ against MCF-10A and HepG2 cell lines, respectively, correlating with its poor enzymatic selectivity of 2.7. Overall, the good in vitro toxicity data paired with the indiscriminate enzymatic and cellular activity of the extended acid compounds such as $\mathbf{2}$ and $\mathbf{1 4}$ are promising lead compounds for future safety and efficacy studies.

The general lack of cytotoxicity with these compounds may be attributed to the unique way in which human DHFR is regulated. It is well known that anticancer antifolates, for instance, require extraordinary target-level potency (MTX, Ki approximately $5 \mathrm{pM})^{23}$ as a consequence of rapid changes to DHFR protein levels. Bastow ${ }^{24}$ was the first to report that MTX treatment increased the expression level of DHFR without affecting the levels of its mRNA. It was later shown that this upregulation was specific to humans ${ }^{25}$ and involved DHFR directly binding its cognate mRNA in the coding region ${ }^{26}$. Moreover, DHFR translational upregulation is an intrinsic form of resistance that protects human cells from MTX toxicity ${ }^{27}$. This may be the one reason that low dose MTX is well tolerated enough to allow for therapeutic applications outside of oncology. For example, it is the first-line treatment for rheumatoid arthritis ${ }^{28}$ and is used in the management of psoriasis ${ }^{29}$ and ulcerative colitis ${ }^{30}$. We have determined that this effect is mirrored by treatment of HL-60 
cells with both 14 and MTX but not iclaprim. This indicates that MTX and INCAs induce a concentration dependent translation of human DHFR, potentially protecting the cells from the anti-HuDHFR enzymatic activity of these compounds (Supplemental Figure S3).

\section{Structural and Computational Studies}

To aid in the understanding of the observed efficacy and to guide future optimization efforts, several crystal structures with lead compound, 14, bound to the wild type $S$. aureus DHFR were solved. Crystals of DfrB:NADPH:14 diffracted to 1.65A. Data collection and refinement statistics are presented in Table S2. The structure of the DfrB:NADPH:14 complex revealed the standard five hydrogen bonding interactions between the 6-ethyldiaminopyrimidine and Asp27 side chain $(2.6 \AA$ and $3.1 \AA$ ), an active site water $(3.0 \AA)$,

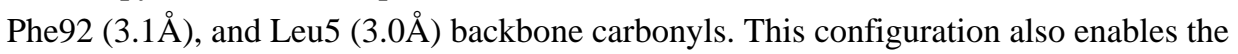
compound to form several hydrophobic interactions between the Phe92, Leu28, Val31, Ile50 and Leu54 side chains. Additionally, the carboxylic moiety extends to form the intended dual hydrogen bonding interactions with the Arg57 side chain, one at $2.6 \AA$ and the other at 3.1 A, Figure 3 panel B.

Comparisons of its benzoic acid counterpart, 13 (PDB ID:5JG0) ${ }^{10}$, reveal that the extension to phenyl acetic acid results in a $1.2 \AA$ displacement of the distal phenyl ring towards the Val31 helix. Compound $\mathbf{1 4}$ sits slightly above $\mathbf{1 3}, 0.7 \AA$ closer to the NADPH binding pocket and this results in $2.2 \AA$ shift in the dioxolane binding. Despite the observed changes in the inhibitor binding mode, the protein's active site appears to accommodate the altered binding positions by maintaining the rotamer orientations and hydrophobic interactions between Leu54, Leu5, Leu28 and Ile50. An overlay of these structures is presented in the Supplemental Information, Figure S4. Additionally, a detailed molecular dynamics analysis of the conformational reorganization that these ligands undergo upon DHFR binding is presented in the supplemental materials.

Crystals of DfrB complexed with NADPH and methotrexate diffracted to $1.80 \AA$. This structure shows two hydrogen bonding interactions between pterin rings and the side chain

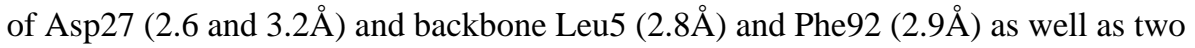
hydrogen bonding interactions with Arg57 (2.7 and 2.8 $)$. Like in the human DHFR structures, the pterin binds in an opposite orientation than that of folate facilitating the hydrogen bonding interaction with Phe92 (PDB ID 3FRD ${ }^{31}$, Supplemental Figure S5). Interestingly, in the MTX structure a rotamer of Leu28 makes more extensive hydrophobic interactions to the benzamide moiety of MTX than in the INCAs, as the binding position of the distal ring would likely clash with that residue.

In order to better understand the molecular interactions between the INCA compounds and DfrG, we constructed a homology model of DfrG active site based on the crystal structure of DfrB bound to 14 and NADPH. DfrG was selected as a model for this study because it is the most prevalent of the three resistance determinants and shares close homology to DfrK. This homology model shows good overlay between the DfrB and DfrG active sites binding to $\mathbf{1 4}$, Figure 4. The DfrG structure maintains the seven hydrogen bonding interactions including

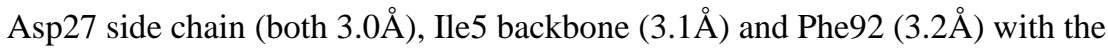


diaminopyrimidine and dual hydrogen bonding interactions between Arg57 and distal phenyl acetic acid (2.9 $\AA$ and $2.7 \AA)$. The hydrophobic interactions with the Val31, Ile50 and Phe92 are also maintained in these structures.

DfrG, as well as DfrK and DfrA, carry an isoleucine instead of the wildtype leucine at the $5^{\text {th }}$ position. This substitution isn't believed to contribute to antifolate resistance as the peptide backbone participates in ligand bonding and this hydrogen bond seems unperturbed by this change. The DfrG contains a Trp28 substitution (Leu28 in DfrB), which increases the

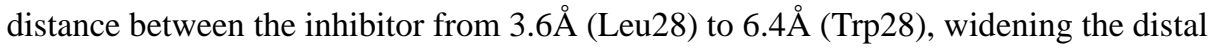
region of the active site and effectively reducing the hydrophobic interactions with $\mathbf{1 4}$. Despite the loss of hydrophobic interactions between 14 and Trp28, 14 is able to maintain equipotent activity against the two isoforms with $K_{i}$ values of 2.00 and 3.2nM for DfrB and DfrG. This homology model indicates that our phenyl acetic acid compounds are able to engage Arg57 in the resistant isoforms and is likely responsible for their improved whole cell and enzyme activity compared to lipophilic antifolates.

\section{Conclusion}

Recent identification of trimethoprim resistance mechanisms in $S$. aureus has prompted us to pursue the development of pan-DHFR inhibitors. Herein, we have been able to develop a hybrid class of antifolates that capture a key electrostatic interaction common to classical antifolates without compromising the bacterial permeability associated with lipophilic antifolates. Moreover, structure-activity relationships indicate that it should still be possible to achieve target-level selectivity and avoid whole cell toxicity even when exploiting this highly conserved interaction. It is noteworthy that developing compounds that simultaneously target both the endogenous and acquired enzymes has been a successful approach for the treatment of MRSA. Fifth generation cephalosporins target the both the endogenous PBPs as well as the acquired resistance determinant, PBP2a. These compounds work through a unique mechanism in which one molecule of the compound binds an allosteric site allowing for a second molecule to access the active site ${ }^{31,32}$. These compounds serve as a model for the continued development of dual targeting agents.

Crystal structures of the INCA compounds disclosed here indicate several highly coordinated hydrogen bonding interactions between the inhibitor and enzyme active site, several of which have, until now, been exclusive to classical antifolates. Adding ionic functionality to earlier generations of this antifolate class revealed a highly coordinated water network between the distal region of the inhibitor and the Arg57 residue of DfrB. Now, through structure based drug design, we have identified the optimal propargylic, proximal and distal substitutions to fully exploit the substrate binding pocket and gain potent activity across trimethoprim sensitive and resistant DHFR isoforms. Having identified several lead compounds, we can continue to improve and evaluate selectivity, determine and optimize pharmacokinetic properties and assess in vivo efficacy. 


\section{Experimental}

\section{Chemical Matter in This Study}

Compounds 8, 9, and $\mathbf{1 3}$ have been previously disclosed ${ }^{10,14}$. All novel compounds have been synthesized following published methods ${ }^{14}$. More thorough methods and compound characterization can be found in the Supplemental Information.

\section{Minimum Inhibitory Concentrations}

Minimum inhibitory concentrations (MICs) for trimethoprim (Sigma Aldrich), iclaprim, and INCA compounds (all in DMSO) were determined following CLSI broth dilution guidelines using isosensitest broth and an inoculum of $5 \times 10^{5} \mathrm{CFU} / \mathrm{mL}^{34}$. MIC values were determined as the lowest concentration of inhibitor to prevent visible cell growth after 18 hour incubation at $37^{\circ} \mathrm{C}$.

\section{Enzymatic Activity and Inhibition Assays}

Enzyme activity was determined by monitoring the rate of NADPH oxidation following published methods ${ }^{10,13,14}$. Assays are performed at room temperature in a buffer solution 20 $\mathrm{mM}$ TES, $\mathrm{pH} 7.5,50 \mathrm{mM} \mathrm{KCl}, 0.5 \mathrm{mM}$ EDTA, $10 \mathrm{mM}$ beta-mercaptoethanol and $1 \mathrm{mg} / \mathrm{mL}$ BSA. For enzymatic assays ( $500 \mu \mathrm{L}$ volume reactions), $1 \mu \mathrm{g}$ of protein is mixed with 100 $\mu \mathrm{M}$ of NADPH and the reaction is activated with $100 \mu \mathrm{M}$ DHF (in $50 \mathrm{mM}$ TES, $\mathrm{pH}$ 7.0). The reaction is monitored in a spectrophotometer at $\mathrm{A}_{340}$. The steady-state kinetic parameters of $\mathrm{K}_{\mathrm{M} \text { (DHF) }}$ and $\mathrm{K}_{\mathrm{i}}$ (DHF) were obtained for TMP $\mathrm{T}^{\mathrm{R}}$ enzymes and compared to the wild type DHFR. Michaelis-Menten constants $\left(\mathrm{K}_{\mathrm{M}}\right.$ and $\left.\mathrm{V}_{\max }\right)$ were graphically determined for the substrate from the initial rates at various DHF concentration (1.6 to $100 \mu \mathrm{M})$ and NADPH saturation $(100 \mu \mathrm{M})$, using a non-linear least-squares fitting procedure ${ }^{35}$. The turnover number $\left(k_{\text {cat }}\right)$ was calculated on the basis of the enzyme molecular mass. $K_{i \text { DHF values were }}$ obtained using Cheng-Prusoff equation ${ }^{36}$. The reported data are averages of two independent experiments, where each experiment was conducted in triplicates.

For enzyme inhibition experiments, $1 \mu \mathrm{g}$ of protein is mixed with $100 \mu \mathrm{M}$ of NADPH and varying concentrations of inhibitor for 5 minutes. After 5 minutes, the reaction is activated with $100 \mu \mathrm{M}$ DHF (in 50mM TES, $\mathrm{pH} 7.0$ ) and monitored at $\mathrm{A}_{340}$. The $\mathrm{IC}_{50}$ is defined as the concentration of compound required to reduce the activity of protein by $50 \%$. For comparisons across Dfr species, the $\mathrm{IC}_{50}$ values are converted to $K_{i}$ to account for differing substrate affinities

\section{HepG2 and MCF-10 Cytotoxicity}

Adherent cell lines were maintained in Eagle's Minimal Essential Media with $2 \mathrm{mM}$ glutamine and Earle's Balanced Salt Solution adjusted to contain $1.5 \mathrm{~g} / \mathrm{L}$ sodium bicarbonate, $0.1 \mathrm{mM}$ non-essential amino acids, $1 \mathrm{mM}$ sodium pyruvate and $10 \%$ fetal calf serum. Fetal calf serum used in these assays was lot matched throughout. All cultures were maintained under a humidified $5 \% \mathrm{CO}_{2}$ atmosphere at $37^{\circ} \mathrm{C}$, had media refreshed twice weekly and were subcultured by trypsinization and resuspension at a ratio of 1:5 each week. Toxicity assays were conducted between passages $10-20$. Target compound toxicity was measured by incubating the test compound with the cells for four hours, washing the cells 
and finally treating the cells with Alamar Blue. After $12-24$ hours the fluorescence of the reduced dye was measured. Fluorescence intensity as a function of test compound concentration was fit to the Fermi equation to estimate $\mathrm{IC}_{50}$ values.

\section{Protein Preparation}

Purification for all proteins in this study have been previously published ${ }^{10,13,14,37}$. In brief, proteins were expressed in BL21(DE3) E. coli cells with 1mM IPTG induction and 18 hour post induction growth at $18^{\circ} \mathrm{C}$. Cells were lysed via sonication in a buffer of $25 \mathrm{mM}$ Tris, $\mathrm{pH}$ 8.0, $0.4 \mathrm{M} \mathrm{KCl}$ supplemented with $0.1 \mathrm{mg} / \mathrm{mL}$ lysozyme, DNase, RNase and a cOmplete Mini Protease Inhibitor tablet. Enzymes were purified using Ni-NTA chromatography washing the bound protein with a solution of $25 \mathrm{mM}$ Tris, $\mathrm{pH} 8.0$ and $0.4 \mathrm{M} \mathrm{KCl}$. Protein was eluted with $25 \mathrm{mM}$ Tris, pH 8.0, $0.3 \mathrm{M} \mathrm{KCl}, 20 \%$ glycerol, $0.1 \mathrm{mM}$ EDTA, $5 \mathrm{mM}$ DTT and $250 \mathrm{mM}$ imidazole. Elution fractions were run on SDS-PAGE gel and pure protein was pooled and desalted into a buffer of $25 \mathrm{mM}$ Tris, $\mathrm{pH}$ 8.0, $0.1 \mathrm{M} \mathrm{KCl}, 0.1 \mathrm{mM}$ EDTA and 2 $\mathrm{mM}$ DTT and flashed frozen for storage at $-80^{\circ} \mathrm{C}$.

\section{Protein Crystallography}

DfrB:NADPH:MTX—DfrB at $13 \mathrm{mg} / \mathrm{mL}$ was incubated with $1 \mathrm{mM}$ of MTX (in DMSO) and $2 \mathrm{mM}$ of NADPH (in water) for several hours. The solution was pelleted at $4{ }^{\circ} \mathrm{C}$ to remove any insoluble or precipitated protein. The protein was crystallized at $4{ }^{\circ} \mathrm{C}$ in a $1: 1$ ratio in a solution of 0.1 M MES, pH 5.5, 0.2 M sodium acetate, 15\% PEG 10,000 (Hampton Research) and 20\% gamma-butyrolactone (Sigma Aldrich) as an additive. Crystals generally grew within 7 days and were flash frozen in solution containing $25 \%$ glycerol.

DfrB:NADPH:14-DfrB at $13 \mathrm{mg} / \mathrm{mL}$ was incubated with $1 \mathrm{mM}$ of 14 (in DMSO) and $2 \mathrm{mM}$ of NADPH (in water) for several hours. The solution was pelleted at $4^{\circ} \mathrm{C}$ to remove any insoluble or precipitated protein. The protein was crystallized at $4^{\circ} \mathrm{C}$ in a $1: 1$ ratio in a solution of $0.1 \mathrm{MES}, \mathrm{pH} 6.0,0.1 \mathrm{M}$ sodium acetate, $15 \%$ PEG 10K and 20\% gammabutyrolactone as an additive. Crystals generally grew within 7 days and were flash frozen in solution containing $25 \%$ glycerol.

All data were collected at Stanford Synchrotron Radiation Light (SSRL), SLAC National Accelerator Laboratory. Data were indexed using HKL2000. Phaser was used to identify molecular replacement solutions using PDB ID: $3 \mathrm{~F} 0 \mathrm{Q}^{37-40}$.

\section{DfrG:NADPH:14 Homology Modelling}

Homology modeling of DfrG active site was accomplished via the study of extant DHFR crystal structures in complex with various ligands. In this case, the DfrB:NADPH:14 crystal structure was selected as the input starting structure for the homology modeling of DfrG active sites. Next, an intermediate model was generated using a structure prediction calculation, termed "OSPREY-designed sequence replacement" (ODSR). This process involves mutation to the target sequence implemented by side chain replacement. Here, all residues within $8 \AA$ of $\mathbf{1 4}$ were selected and mutated to the appropriate $\mathrm{DfrG}$ amino acid, determined by sequence alignment to the sequence of DfrG. Sequence alignment was performed using CLUSTAL X 2.1 software $^{41}$. Subsequently, side-chain replacement and 
global minimum energy conformation (GMEC) calculation were performed using OSPREY $^{42,43}$. Following ODSR, the intermediate model was all-atom minimized using the SANDER package from the AMBER biomolecular simulation package ${ }^{44}$. Minimization was allowed to proceed for 1,000 steps, resulting in a fully-minimized homology model for DfrG active sites in complex with $\mathbf{1 4}$ and NADPH. Scripts are available upon request for all steps in our protocol.

\section{Supplementary Material}

Refer to Web version on PubMed Central for supplementary material.

\section{Acknowledgements}

We would like to acknowledge Kelly Huynh for her discussions during the prepapartaion of this manuscript. This study was funded by the National Institutes of Health grants GM118543 and GM078031 to BRD and AI111957 and AI104841 to DLW. We also acknowledge the SSRL beamline staff for their assistance in remote data collection and crystallography support. Use of the Stanford Synchrotron Radiation Lightsource, SLAC National Accelerator Laboratory, is supported by the U.S. Department of Energy, Office of Science, Office of Basic Energy Sciences under Contract No. DE-AC02-76SF00515.

\section{Abbreviations used}

$\begin{array}{ll}\text { TMP } & \text { Trimethoprim } \\ \text { SMX } & \text { Sulfamethoxazole } \\ \text { DHFR } & \text { dihydrofolate reductase } \\ \text { DHF } & \text { dihydrofolate } \\ \text { MTX } & \text { methotrexate } \\ \text { IC } 50 & \text { concentration for 50\% inhibitory activity } \\ \text { MIC } & \text { Minimum inhibitory concentrations } \\ \text { TMPR } & \text { Trimethoprim resistant }\end{array}$

\section{References}

1. O’Neil J (2014) Antimicrobial Resistance: Tackling a crisis for the health and wealth of Nations. Review on Antimicrobial Resistance

2. Frieden T Antibiotic resistance threats. Centers for Disease Control 22-50 (2013).

3. Center for Disease Control and Prevention (2013) Outpatient antibiotic prescriptions - United States.

4. Huang DB, Noviello S, Blaser B, Scaramucci A, Corey GR (2019) A Pooled Analysis of the Safety and Efficacy of Iclaprim Versus Vancomycin for the Treatment of Acute Bacterial Skin and Skin Structure Infection in Patients With Intravenous Drug Use: Phase 3 REVIVE Studies. Clin Ther, 41 1090-1096. DOI: 10.1016/j.clinthera.2019.04.004 [PubMed: 31030995]

5. Dale GE, Broger C, Hartman PG, Langen H, Page MG, Then RL, Stüber D (1995) Characterization of the gene for the chromosomal dihydrofolate reductase (DHFR) of Staphylococcus epidermidis ATCC 14990: The origin of the trimethoprim-resistant S1 DHFR from Staphylococcus aureus? J. Bacteriology, 17 2965-2970. DOI:0.1128/jb.177.11.2965-2970.1995 
6. Vickers AA, Potter NJ, Fishwick CWG, Chopra I, O’Neill AJ (2009) Analysis of mutational resistance to trimethoprim in Staphylococcus aureus by genetic and structural modelling techniques. J. Antimicrob. Chemother 63, 1112-1117. DOI:10.1093/jac/dkp090 [PubMed: 19383727]

7. Nurjadi D, Olalekan AO, Layer F, Shittu AO, Alabi A, Ghebremedhin B, Schaumburg F, HofmannEifler J, Van Genderen PJ, Caumes E, Fleck R, Mockenhaupt FP, Herrmann M, Kern WV, Abdulla S, Grobusch MP, Kremsner PG, Wolz C, Zanger P 2014 Emergence of trimethoprim resistance gene dfrG in Staphylococcus aureus causing human infection and colonization in sub-Saharan Africa and its import to Europe. J. Antimicrob. Chemother 69, 2361-2368. DOI:10.1093/jac/dku174 [PubMed: 24855123]

8. Sekiguchi J, Tharavichitkyl P, Miyoshi-Akiyama T, Vhupia V, Fujino T, Araake M, Irie A, Morita K, Kuratsuji T, Kirikae T (2005) Cloning and Characterization of a Novel Trimethoprim-Resistant Dihydrofolate Reductase from a Nosocomial Isolate of Staphylococcus aureus CM.S2 (IMCJ1454). Antimicrob. Agents Chemother 49, 3948-3951. DOI:10.1128/AAC.49.9.3948-3951.2005 [PubMed: 16127079]

9. Brennan GI, Abbott Y, Burns A, Leonard F, McManus BA, O’Connell B (2016) The Emergence and Spread of Multiple Livestock-Associated Clonal Complex 398 Methicillin-Resistant and Methicillin-Susceptible Staphylococcus aureus Strains among Animals and Humans in the Republic of Ireland, 2010-2014. PLoS One 11, e0149396 DOI:10.1371/journal.pone.0149396 [PubMed: 26886749]

10. Reeve SM, Scocchera EW, G-Dayanadan N, Keshipeddy S, Krucinska J, Hajian B, Ferreira J, Nailor M, Aeschlimann J, Wright DL, Anderson AC 2016 MRSA Isolates from United States Hospitals Carry dfrG and dfrK Resistance Genes and Succumb to Propargyl-Linked Antifolates. Cell Chem. Biol 23, 1458-1467. DOI:10.1016/j/chembiol2016.11.007 [PubMed: 27939900]

11. Coelho C, de Lencastre H, Aires-de-Sousa M (2017) Frequent occurrence of trimethoprimsulfamethoxazole hetero-resistant Staphylococcus aureus isolates in different African countries. Eur. J. Clin. Microbiol. Infect. Dis 36, 1243-1252. DOI: 10.1007/s10096-017-2915-x [PubMed: 28160148]

12. Nurjadi D, Schäfer J, Friedrich-Jänicke B, Mueller A, Neumayr A, Calvo-Cano A, Goorhuis A, Nolhoek N, Lagler H, Kantele A, Van Genderen PJJ, Gascon J, Grobusch MP, Caumes E, Hatz C, Fleck R, Mochenhaupt FP, Zanger P (2015) Predominance of $d f r G$ as determinant of trimethoprim resistance in imported Staphylococcus aureus. Clin. Micro and Infection 21, 1095.re5-1095.e9. DOI: 10.1016/j.cmi.2015.08.021

13. Keshipeddy S, Reeve SM, Anderson AC, Wright DL (2015) Nonracemic Antifolates Stereoselectively Recruit Alternate Cofactors and Overcome Resistance in S. aureus J. Amer. Chem. Soc 137, 8983-8990. DOI:10.1021/jacs.5b01442f [PubMed: 26098608]

14. Scocchera E, Reeve SM, Keshipeddy S, Lombardo MN, Hajian B, Sochia AE, Alverson JB, Priestley ND, Anderson AC, Wright DL. 2016 Charged Nonclassical Antifolates with Activity Against Gram-Positive and Gram-Negative Pathogens. ACS Med. Chem. Lett 7, 692-696. DOI: 10.1021/acsmedchemlett.6b00120 [PubMed: 27437079]

15. Lamb K, Lombardo MN, Alverson J, Priestley N, Wright D, Anderson AC (2014) Crystal structures of Klebsiella pneumoniae dihydrofolate reductase bound to propargyl-linked antifolates reveal features for potency and selectivity. Antimicrob. Agents Chemother 58, 7484-7491. DOI: 10.1128/AAC.03555-14. [PubMed: 25288083]

16. Lombardo MN, G-Dayanandan N, Wright DL, Anderson AC. 2016 Crystal Structures of Trimethoprim-Resistant DfrA1 Rationalize Potent Inhibition by Propargyl-Linked Antifolates. ACS Infect Dis acsinfecdis.5b00129.

17. Hajian B, Scocchera E, Keshipeddy S, G-Dayanandan N, Shoen C, Krucinska J, Reeve S, Cynamon M, Anderson AC, Wright DL (2016) Propargyl-linked antifolates are potent inhibitors of drug-sensitive and drug-resistant mycobacterium tuberculosis. PLoS One 11, 1-14. DOI: 10.1371/ journal.pone.0161740

18. Reeve SM, Scocchera E, Ferreira J, G-Dayanandan N, Keshipeddy S, Wright DL, Anderson AC 2016 Charged Propargyl-linked Antifolates Reveal Mechanisms of Antifolate Resistance and Inhibit Trimethoprim-Resistant MRSA Strains Possessing Clinically Relevant Mutations. J. Med. Chem 59, 6493-6500 DOI: 10.1021/acs.jmedchem.6b00688 [PubMed: 27308944] 
19. Heaslet H, Harris M, Fahnoe K, Sarver R, Putz H, Chang J, Subramanyam C, Barreiro G, Miller JR (2009) Structural comparison of chromosomal and exogenous dihydrofolate reductase from Staphylococcus aureus in complex with the potent inhibitor trimethoprim. Proteins, 76, 706-717. DOI: 0.1002/prot.22383 [PubMed: 19280600]

20. Pelphrey PM, Popov VM, Joska TM, Beierlein JM, Bolstad ESD, Fillingham YA, Wright DL, Anderson AC (2007) Highly Efficient Ligands for Dihydrofolate Reductase from Cryptosporidium hominis and Toxoplasma gondii Inspired by Structural Analysis. J. Med. Chem 50, 940-950. DOI: 10.1021/jm061027h [PubMed: 17269758]

21. Lewis WS, Cody V, Galitsky N, Luft JR, Pangborn W, Chunduru SK, Spencer HT, Appleman JR, Blakely RL (1995) Methotrexate resistant variants of Human Dihydrofolate Reductase with Substitutions of Leucine 22. Kinetics, crystallography, and potential of selectable markers. J. Biol Chem, 270, 5057-5064. DOI: 0.1074/jbc.270.10.5057 [PubMed: 7890613]

22. Chan DCM, Fu H, Forsch RA, Queener SF, and Rosowsky A (2005) Design, Synthesis, and Antifolate Activity of New Analogues of Piritrexim and Other Diaminopyrimidine Dihydrofolate Reductase Inhibitors with $\omega$-Carboxyalkoxy or $\omega$-Carboxy-1-alkynyl Substitution in the Side Chain. J. Med Chem 48, 4420-4431. DOI: 10.1021/jm0581718 [PubMed: 15974594]

23. Assaraf YG (2007) Molecular basis of antifolate resistnace. Cancer and Metastasis Reviews. 26, 153-181. DOI: 10.1007/s10555-007-9049-z [PubMed: 17333344]

24. Bastow KF, Prabhu R, Cheng YC (1984) The Intracellular Content Of Dihydrofolate Reductase: Possibilities for Control and Implicationsfor Chemotherapy. Adv. Enzyme Regul 22, 15-26. DOI: 10.1016/0065-2571(84)90006-2 [PubMed: 6475640]

25. Hsieh YC, Skacel NE, Bansal N, Scotto KW, Banerjee D, Bertino JR, Abali EE (2009) SpeciesSpecific Differences in Translational Regulation of Dihydrofolate Reductase. Molecular pharmacology, 76, 723-733. DOI:10.1124/mol.109.055772 [PubMed: 19570950]

26. Skacel N, Menon LG, Mishra PJ, Peters R, Banerjee D, Bertino JR, Abali EE (2005). Identification of amino acids required for the functional up-regulation of human dihydrofolate reductase protein in response to antifolate treatment. J. Biol. Chem 280, 22721-22731. (2005). DOI: 10.1074/ jbc.M500277200 [PubMed: 15817466]

27. Zhang K, Rathod PK (2002) Divergent regulation of dihydrofolate reductase between malaria parasite and human host. Science, 296, 545-547. DOI:10.1126/science.1068274 [PubMed: 11964483]

28. Shinde CG, Venkatesh MP, Kumar TMP, Shivakumar HG (2014) Methotrexate: A gold standard for treatment of rheumatoid arthritis. J. Pain and Palliat. Care Pharmaco, 28, 351-358. DOI: $10.3109 / 15360288.2014 .959238$

29. Yélamos O, Puig L (2015) Systemic methotrexate for the treatment of psoriasis. Expert Rev. Clin. Immun 11, 553-563. DOI: 10.1586/0411333X.2015.1026894

30. Gabbani T, Deiana S, Lunardi S, Manetti N, Annese V (2016) Safety profile of methotrexate in inflammatory bowel disease. Expert Opin. Drug Saf 15, 1427-1437. DOI: 10.1080/14740338.2016.1218468 [PubMed: 27462711]

31. Oefner C, Bandera M, Haldimann A, Laue H, Schulz H, Mukhija S, Parisi S, Weiss L, Lociuro S, Dale GE (2009) Increased hydrophobic interactions of iclaprim with Staphylococcus aureus dihydrofolate reductase are responsible for the increase in affinity and antibacterial activity. J. Antimicrob. Chemother 63, 687-698. DOI: 10.1093/jac/dkp024 [PubMed: 19211577]

32. Villegas-Estrada A, Lee M, Hesek D, Vakulenko SB, Mobashery S (2008) Co-opting the Cell Wall in Fighting Methicillin-Resistant Staphylooccus aureus: Potent Inhibition of PBP 2a by Two AntiMRSA B-Lactam Antibiotics. J. Am. Chem. Soc 130, 9212-9213. DOI: 10.1021/ja8029448 [PubMed: 18582062]

33. Otero LH, Rojas-Altuve A, Llarrul LI, Carrasco-Lopez C, Kumarasiri M, Lastochkin E, Fishovitz J, Dawley M, Hesek D, Lee M, Johnson JW, Fisher JF, Chang M, Mobashery S, Hermoso JA (2013) How allosteric control of Staphylococcus aureus penicillin binding protein 2a enables methicillin resistance and physiological function. Proc. Natl. Acad. Sci. USA, 110, 16808-16813. DOI: 10.1073/pnas.1300118110 [PubMed: 24085846]

34. National Committee for Clinical Laboratory Standards. 2014 CLSI Performance standard of Antimicrobial Susceptibility Testing: Twenty-fourth International Supplement. National Committee for Clinical Laboratory Standards, Wayne, PA. 
35. Swift ML (1997) GraphPad Prism, Data Analysis and Scientific Graphing. J. Chem. Infor. Comput. Sci 37, 411-412. DOI:10.1021/ci960402j

36. Cheng Y, Prusoff WH (1973) Relationship between the inhibition constant (KI) and the concentration of inhibitor which cause 50 per cent inhibition (IC50) of an enzymatic reaction. Biochem. Pharm 22, 2099-3108. DOI: 10.1016/0006-2952(73)90196-2.

37. Frey KM, Georgiev I, Donald BR, Anderson AC (2010) Predicting resistance using protein design algorithms. Proc. Nat. Acad. Sci 107, 13707-13712. DOI: 10.1073/pnas.1002162107 [PubMed: 20643959]

38. Otwinowski Z and Minor W (1997) Processing of X-ray Diffraction Data Collected in Oscillation Mode. Methods in Enzymology, 276, 307-326. DOI: 10.1016/S0076-6879(97)76066-X

39. McCoy AJ, Grosse-Kunstleve RW, Adams PD, Winn MD Storoni LC Read RJ (2007) Phaser Crystallographic software. J. Appl. Cryst 40, 658-674. DOI:10.1170/S0021889807021206 [PubMed: 19461840]

40. Adams PD, Afonine PV, Bunkóczum G, Chen VB, Davis IW, Echols N, Headd JJ, Hung L-W, Kapral GJ, Grosse-Kunstleve RW, McCoy AJ, Moriarty NW, Oeffner R, Read RJ, Richardson DC, Richardson TC, Terwilliger TC, Zwart PH (2010) PHENIX: a comprehensive python-based system for macromolecular structure solution. Acta Cryst, D66, 213-221. DOI:10.1107/ S0907444909052925

41. Larkin MA, Blackshields G, Brown NP, Chenna R, McGettigan PA, McWilliam H, Valentin F, Wallace IM, Wilm A, Lopez R, Thompson TJ, Higgins DG (2007) Clustal W and Clustal X version 2.0. Bioinformatics 23, 2947-2948. DOI: 10.1093/bioinformatics/btm404 [PubMed: 17846036]

42. Gainza P, Roberts KE, Georgiev I, Lilien RH, Keedy DA, Chen C, Reza F, Anderson AC, Richardson DC, Richardson JS, Donald BR (2013) OSPREY: Protein Design with Ensembles, Flexibility and Provable Algorithms. Methods Enzymol 523 27-107. DOI: 10.1016/ B978-0-12-394292-0.00005-9

43. Hallen MA, Martin JW, Ojewole A, Jou JD, Lowegard AU, Frenkel MS, Gainza P, Nisonoff HM, Mukund A, Wang S, Holt GT, Zhou D, Dowd E, Donald BR (2018) OSPREY 3.0: open-Source Protein Redesign for You, with Powerful New Tools. J. Comp. Chem 39, 2494-2507. DOI: 10.1002/jcc.25522 [PubMed: 30368845]

44. Pearlman DA, Case DA, Caldwell JW, Ross WS, Cheatham TE, DeBolt S, Ferguson D, Seibel G, Kollman P (1995) AMBER, a package of computer programs for applying molecular mechanics, normal mode analysis, molecular dynamics and free energy calculations to simulate the structural and energetic properties of molecules. Comp. Phys. Comm 91, 1-41. DOI:

10.1016/0020-4655(95)00041-D 


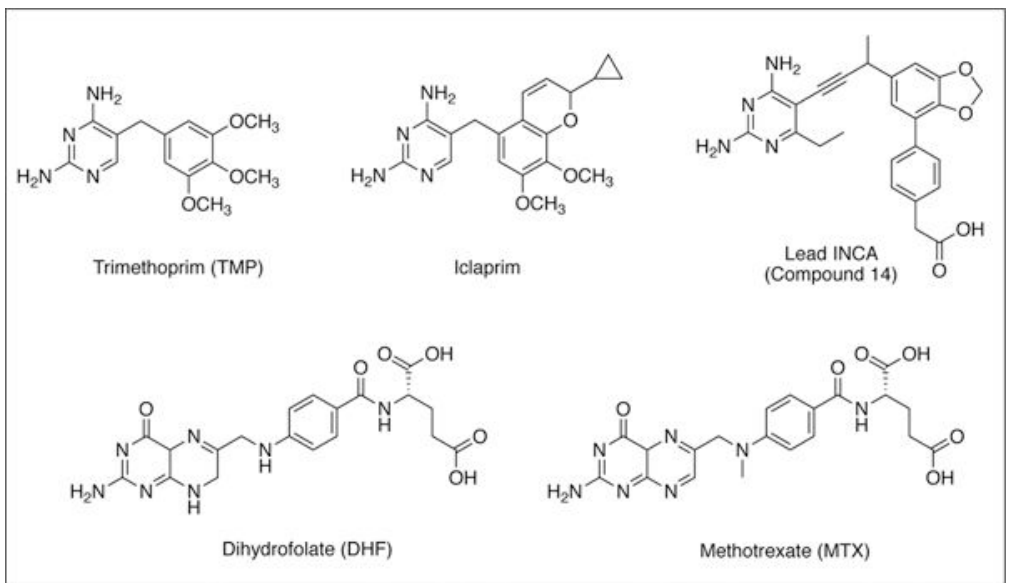

Figure 1:

Structures of antifolates discussed in this study. Trimethoprim and iclaprim (top row) are both lipophilic antifolates with antibacterial activity. Methotrexate is a classical antifolate that mimics the natural substrate dihydrofolate. Compound $\mathbf{1 4}$ is a lead ionized non-classical antifolate (INCA). 


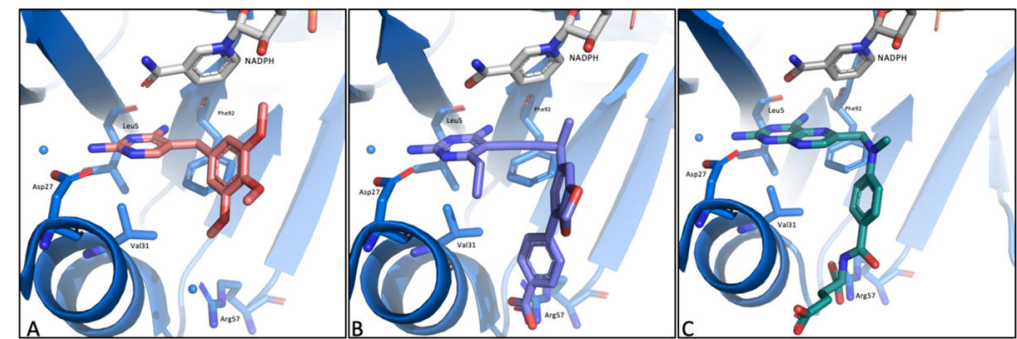

Figure 2:

X-ray crystal structures of antifolates in the DfrB active site A) trimethoprim B) compound $13 \mathrm{C})$ methotrexate 


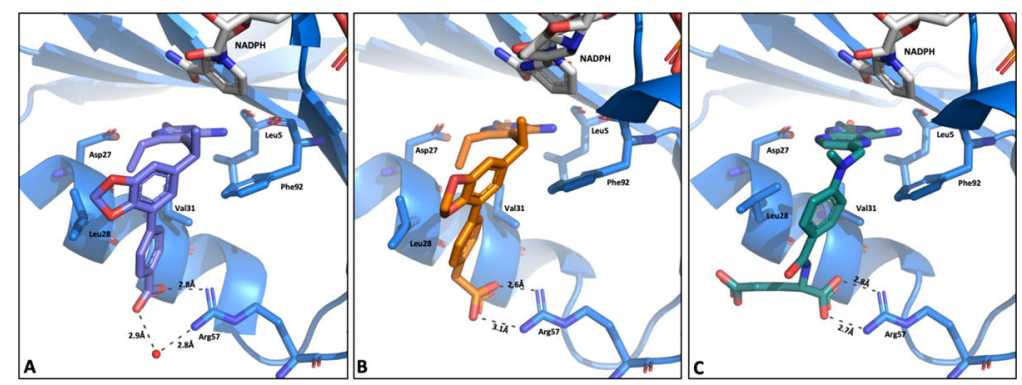

Figure 3:

X-ray crystal structures of A) 13 B) 14 and C) methotrexate in the DfrB active site. This figure emphasizes the interactions between the distal acids of the INCAs/MTX and Arg57 residue. Panel B shows the structural improvement of the phenyl acetic acid inhibitors (panel B) over the benzoic acid series (panel A) and similarity to MTX (panel C). 


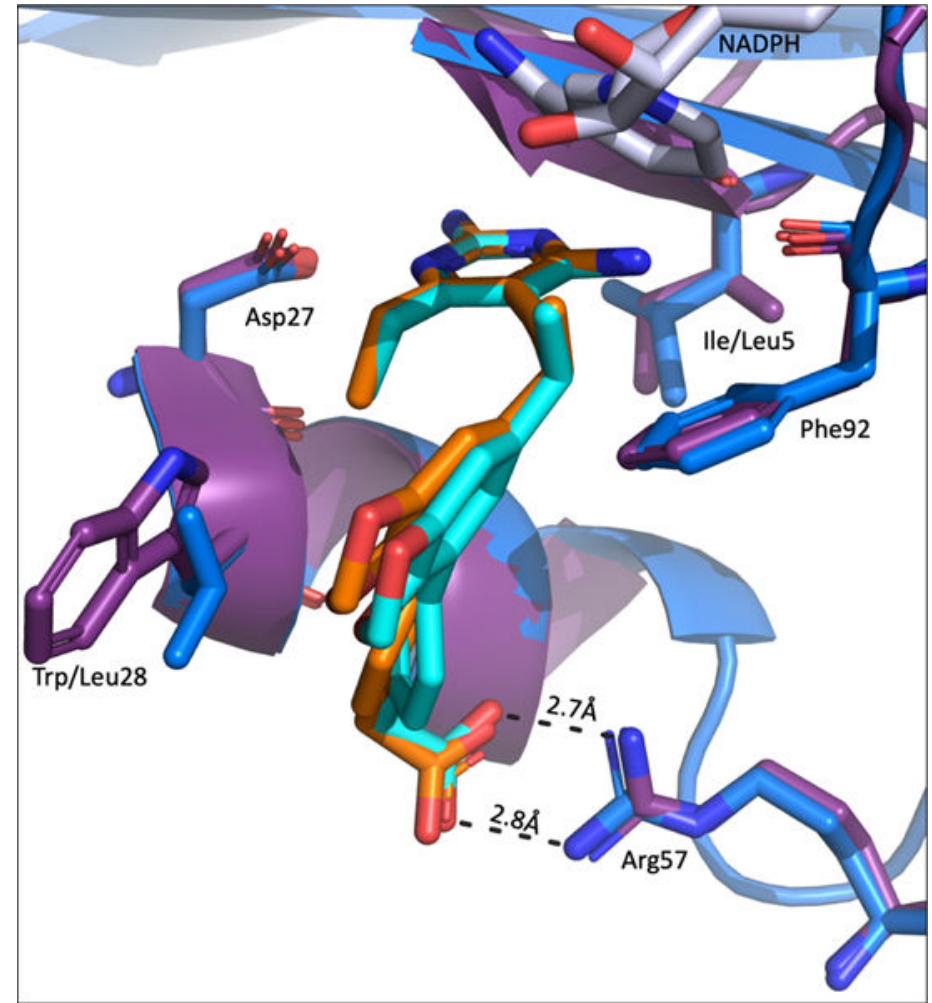

Figure 4:

Overlay of DfrB crystal structure(dark blue) with $\mathbf{1 4}$ (orange) and DfrG homology model (purple) with 14 (teal). Active site residues shown as sticks. 


\section{Table 1}

Staphylococcus aureus strains used in this study

\begin{tabular}{lcccc}
\hline \multirow{2}{*}{ Strain } & \multirow{2}{*}{ TMP $^{\mathrm{R}}$ Determinant } & \multicolumn{3}{c}{ Minimum Inhibitory Concentrations $(\boldsymbol{\mu g} \mathbf{m} \mathbf{m L})$} \\
\cline { 3 - 5 } & & Trimethoprim & Iclaprim & Methotrexate \\
\hline UCH115 & $d f f$ A & 250 & 64 & $>250$ \\
UCH121 & $d f r G$ & $>1000$ & $>250$ & $>250$ \\
HH1184 & $d f r K$ & $>1000$ & $>250$ & $>250$ \\
ATCC43300 & N/A & 0.312 & 0.040 & 125 \\
\hline
\end{tabular}


Table 2

DHFR Enzyme Kinetics and Inhibition with Clinical Antifolates

\begin{tabular}{ccccccc}
\hline & & & \multicolumn{4}{c}{ Enzyme Inhibition $^{\boldsymbol{a}}, \boldsymbol{K}_{\boldsymbol{i}}(\mathbf{n M})$} \\
\hline & $\boldsymbol{K}_{\boldsymbol{M}}$, DHF $(\boldsymbol{\mu M})$ & $\boldsymbol{K}_{\text {cat }}\left(\mathbf{s}^{-\mathbf{1}}\right)$ & $\boldsymbol{K}_{\text {cat }} / \boldsymbol{K}_{\boldsymbol{M}}(\boldsymbol{\mu M} / \mathbf{s})$ & Trimethoprim & Iclaprim & Methotrexate \\
\hline DfrB & 13.4 & 4.66 & 0.34 & $2.7 \pm 0.2$ & $1.8 \pm 0.2$ & $0.71 \pm 0.08$ \\
DfrA & 5.76 & 4.12 & 0.72 & $820 \pm 40$ & $90 \pm 3$ & $0.38 \pm 0.04$ \\
DfrG & 8.9 & 3.57 & 0.40 & $31,000 \pm 1400$ & $1350 \pm 10$ & $1.8 \pm 0.1$ \\
DfrK & 11.0 & 3.82 & 0.35 & $4,260 \pm 200$ & $221 \pm 6$ & $2.47 \pm 0.01$ \\
Human & 10.53 & 3.16 & 0.30 & $7,860 \pm 560$ & $32,500 \pm 500$ & $2.28 \pm 0.01$ \\
\hline
\end{tabular}

${ }^{a} K_{i}$ values are average of two independent experiments performed in triplicate $\pm \mathrm{SD}$ 


\section{Table 3}

Structures of INCA Compounds

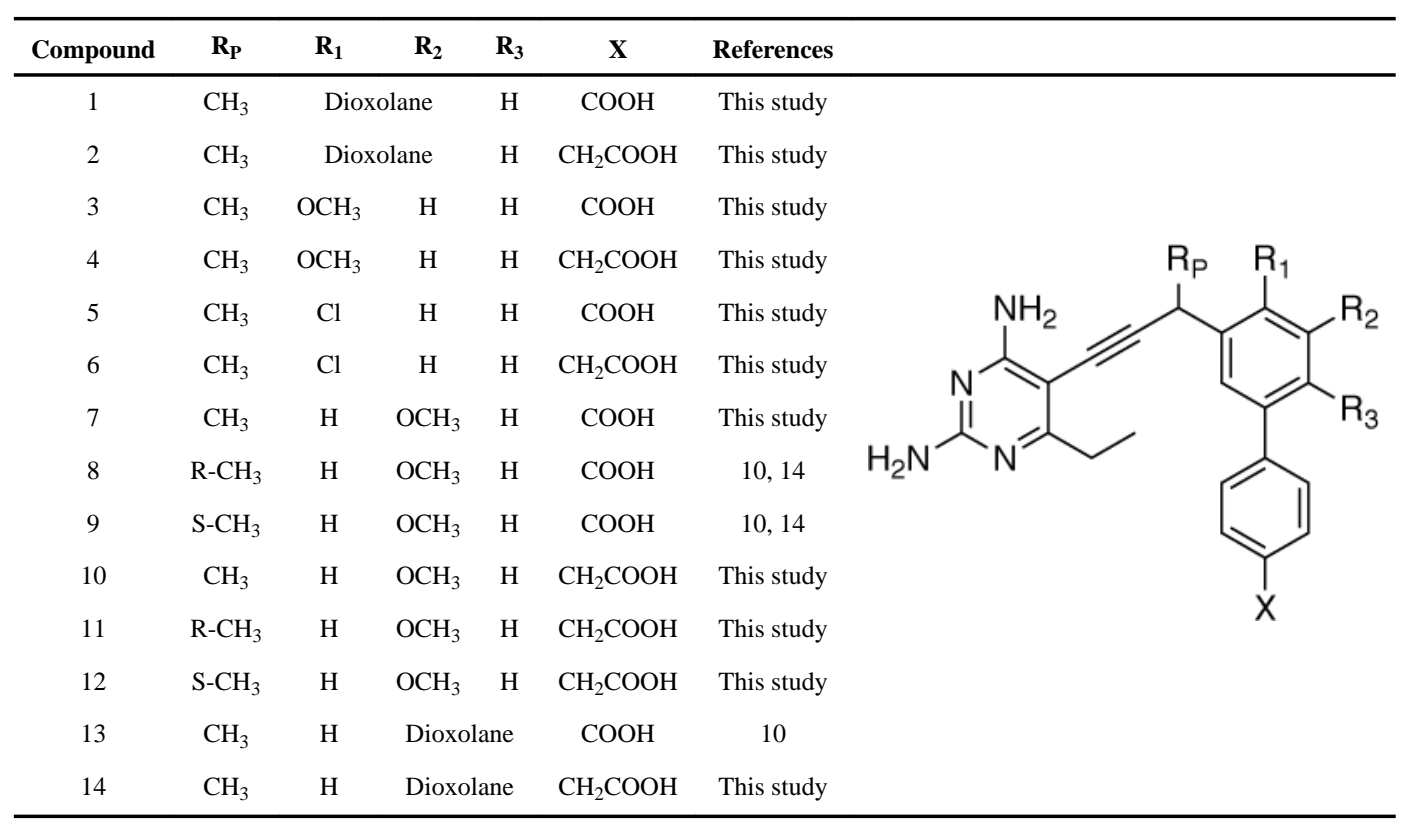




\section{Table 4}

Enzymatic inhibition of Dfr Isozymes by INCA compounds ${ }^{a}\left(K_{i}, \mathrm{nM}\right)$

\begin{tabular}{cccccc}
\hline & DfrB & DfrA & DfrG & DfrK & Human Selectivity \\
\hline 1 & $2.1 \pm 0.1$ & $216 \pm 10$ & $16 \pm 1$ & $15 \pm 2$ & 16.9 \\
2 & $2.98 \pm 0.09$ & $9.8 \pm 0.9$ & 131 & $6.2 \pm 0.2$ & 23.9 \\
3 & $20 \pm 2$ & $520 \pm 30$ & $1550 \pm 140$ & $280 \pm 30$ & 4.4 \\
4 & $6.2 \pm 0.5$ & $11.5 \pm 0.4$ & $260 \pm 20$ & $15.6 \pm 0.6$ & 9.6 \\
5 & $10.4 \pm 0.2$ & $15 \pm 2$ & $7.2 \pm 0.5$ & $1.8 \pm 0.2$ & 2.7 \\
6 & $1.17 \pm 0.01$ & $2.9 \pm 0.1$ & $14 \pm 2$ & $1.6 \pm 0.1$ & 99.2 \\
7 & $1.76 \pm 0.06$ & $9.7 \pm 0.4$ & $13 \pm 1$ & $3.4 \pm 0.3$ & 18.9 \\
8 & $1.08 \pm 0.08$ & $21.8 \pm 0.5$ & $18 \pm 1$ & $3.0 \pm 0.1$ & 50.4 \\
9 & $1.6 \pm 0.1$ & $15 \pm 1$ & $16 \pm 1$ & $9.0 \pm 0.8$ & 46.1 \\
10 & $2.2 \pm 0.2$ & $2.2 \pm 0.2$ & $40 \pm 3$ & $4.2 \pm 0.4$ & 16.7 \\
11 & $2.1 \pm 0.2$ & $3.0 \pm 0.3$ & $73 \pm 3$ & $8.1 \pm 0.4$ & 24.7 \\
12 & $4.0 \pm 0.1$ & $16 \pm 1$ & $15 \pm 1$ & $4.0 \pm 0.2$ & 20.3 \\
13 & $1.17 \pm 0.02$ & $17 \pm 1$ & $6.3 \pm 0.4$ & $4.0 \pm 0.6$ & 74.1 \\
14 & $2.00 \pm 0.07$ & $10.4 \pm 0.8$ & $3.2 \pm 0.5$ & $1.8 \pm 0.2$ & 2.9 \\
MTX & $0.71 \pm 0.08$ & $0.38 \pm 0.04$ & $1.9 \pm 0.1$ & $2.5 \pm 0.1$ & 4.0 \\
\hline
\end{tabular}

${ }^{a} K_{i}$ values are average of three experiments $\pm \mathrm{SD}$

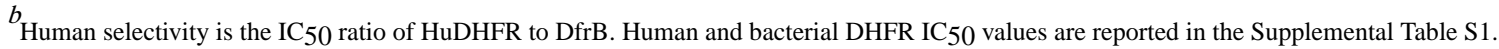


Table 5

Whole Cell Activity and Cytotoxicity of INCA Compounds

\begin{tabular}{|c|c|c|c|c|c|c|}
\hline & \multicolumn{4}{|c|}{ Minimum Inhibitory Concentrations $(\mu \mathrm{g} / \mathrm{mL})$} & \multicolumn{2}{|c|}{ Mammalian Toxicity $\mathrm{IC}_{50}(\mu \mathrm{g} / \mathrm{mL})^{a}$} \\
\hline & ATCC 43300 & UCH115 (dfrA) & $\mathrm{UCH121}(d f r G)$ & HH1184 (dfrK) & MCF10A & HepG2 \\
\hline 1 & 0.005 & $>10$ & 0.625 & 0.312 & $>200$ & $>200$ \\
\hline 2 & 0.0025 & 2.5 & 1.25 & 0.625 & $>200$ & $>200$ \\
\hline 3 & 0.04 & 10 & 10 & 1.25 & $>200$ & $>200$ \\
\hline 4 & 0.04 & 5 & 10 & 1.25 & $167 \pm 3$ & $>200$ \\
\hline 5 & $<0.001$ & 5 & 2.5 & 0.625 & $49.0 \pm 0.7$ & $99 \pm 2$ \\
\hline 6 & $<0.001$ & 2.5 & 2.5 & 0.312 & $166 \pm 6$ & $170 \pm 5$ \\
\hline 7 & 0.004 & 10 & 1.25 & 0.625 & $>200$ & $>200$ \\
\hline 8 & 0.010 & 5 & 0.625 & 0.312 & $169 \pm 3$ & $>200$ \\
\hline 9 & 0.010 & 2.5 & 5 & 2.5 & $\mathrm{ND}^{b}$ & $>200$ \\
\hline 10 & 0.002 & 1.25 & 2.5 & 2.5 & $169 \pm 4$ & $181 \pm 3$ \\
\hline 11 & 0.010 & 1.25 & 10 & 5 & $166 \pm 3$ & $164 \pm 3$ \\
\hline 12 & 0.02 & 5 & 5 & 1.25 & $>200$ & $>200$ \\
\hline 13 & 0.020 & 20 & 0.625 & 0.156 & $>200$ & $>200$ \\
\hline 14 & 0.010 & 2.5 & 0.625 & 0.625 & $>200$ & $>200$ \\
\hline MTX & 125 & $>250$ & $>250$ & $>250$ & $>200$ & $>200$ \\
\hline
\end{tabular}

$a_{\text {Toxicity shown as the average of three independent measurements } \pm \text { SD. }}$

$b_{\text {ND: Not determined }}$ 